\title{
Beads, Beaded-Fibres and Fibres: Tailoring the morphology of poly(caprolactone) using pressurised gyration
}

Xianze Hong, Mohan Edirisinghe, Suntharavathanan Mahalingam*

Department of Mechanical Engineering, University College

London (UCL), London WC1E 7JE, UK

*Corresponding Author, e-mail: suntharavathanan.mahalingam@ucl.ac.uk

\begin{abstract}
This work focuses on forming bead on string poly(caprolactone) (PCL) by using gyration under
\end{abstract} pressure. The fibre morphology of bead on string is an interesting feature that falls between bead-free fibres and droplets, and it could be effectively controlled by the rheological properties of spinning dopes and the major processing parameters of the pressurised gyration system which are working pressure and rotating speed. Bead products were not always spherical in shape and tender to be more elliptical, therefore both their width and length were measured. The average bead width and length produced spanned a range $145-660 \mu \mathrm{m}$ and 140 - $1060 \mu \mathrm{m}$, respectively. The average distance between two adjacent beads (i.e. inter-bead distance) and the bead size (width and length) are shown to be a function of processing parameters and polymer concentration. An interesting morphology i.e. beads with short fibre was observed when using a high polymer concentration. Bead on string structure agglomeration was promoted by a low polymer concentration. Formation of droplets or agglomerated bead on string is promoted below $5 \mathrm{wt} \%$ polymer concentration, and beads with short fibre were present in the microstructure beyond a polymer concentration of $20 \mathrm{wt} \%$.

Keywords: bead on string; fibre; polymer; pressure; gyration 


\section{Introduction}

Polymer fibres have a vast scope of applications, including biofuel cell, electronics, filtration and mechanical composite material [1-9]. A uniform bead free structure of fibre is usually used, for example in high efficiency filtering membranes, and protective clothing due to its features of large specific surface area, narrow apertures and good mechanical properties. However, for drug delivery systems, the effect of fibrous structures is not as good as particles or bead on string structures in terms of sustained release and target control and carry volume of drugs transported [2]. This is because the fibres with bead on string structure have a relatively higher surface to volume ratio than uniform fibres, so the dissolution rate of drugs in water can be increased i.e. greatly improve the bioavailability of drugs. Moreover the capacity of drug loading could be adjusted by varying bead size (bead formation is able to carry more drugs), hence a bead on string structure is more suitable for playing the role of a drug carrier.

State of the art techniques to fabricate fibres include template synthesis, molecular selfassembly and electrospinning [10-13], with the latter being most popular. Electrospinning takes place via a nozzle carrying polymer solution or melt and generates fibres as the result of the electric field force provided by an external electric field (at the level of $\mathrm{kV}$ ) which exceeds the surface tension force of the polymer solution. One drawback of this method is that mass production is a major challenge. The utilization of multi-nozzles could help to a certain degree but it is a costly operation and still cannot always easily meet large scale manufacturing targets. 
Pressurised gyration is a novel technique that has been used to produce various products e.g. fibres, microbubbles, capsules etc $[14,15]$. It effectively utilizes high speed rotation to extrude several solution jets in parallel from orifices that are located on the vessel surface. The dynamic fluid flow and the governing centrifugal force compete with surface tension of solution to form well aligned polymer fibres [14]. It doesn't, like electrospinning, demand additional requirements on the electrical conductivity and dielectric constant of the polymer solution, and the absence of an applied voltage at $\mathrm{kV}$ level reduces the possibility to form fibres with random orientations. The size, distribution, morphology of fibres are governed by the working pressure and rotation speed, and the homogeneity of fibres are controlled by the polymer solution properties [16]. Furthermore, the spinnability of a polymer solution by pressurised gyration is highly affected by its rheological properties, especially the chain entanglement in the polymer solution.

In the present work we explored the fabrication of beaded PCL fibres using pressurised gyration. Poly( $\varepsilon$-caprolactone) (PCL) is one of the most promising linear aliphatic polyesters used extensively in the biomedical field since it is biodegradable in an aqueous medium and biocompatible in biological applications. This semi-crystalline polymer has a low melting point $\left(60^{\circ} \mathrm{C}\right)$ and a glass transition temperature $\left(-60^{\circ} \mathrm{C}\right)$ and therefore it could be fabricated easily into any shape and size. In particular, we examine a range of polymer concentration and the working parameters required for forming fibres with controllable bead on string structures. 
This could be used in pharmaceutical applications where particle-loaded bead on string fibres could be formed in large quantity by utilizing pressurised gyration (potentially $6 \mathrm{~kg} \mathrm{~h}^{-1}$ of fibre [14]).

\section{Experimental Details}

\subsection{Materials}

Poly ( $\varepsilon$-caprolactone) (PCL) with a molecular weight of 80,000 $\mathrm{gmol}^{-1}$ and acetone (analytical grade) both purchased from Sigma-Aldrich (Poole, UK) were used as received in this work.

\subsection{Solution Preparation and Characterisation}

Six polymer solutions (spinning dopes) were prepared by dissolving $5 \mathrm{wt} \%, 10 \mathrm{wt} \%, 15 \mathrm{wt} \%$, $20 \mathrm{wt} \%, 25 \mathrm{wt} \%, 30 \mathrm{wt} \%$ of PCL pellets in acetone. These were made in a sealed bottle and were subject to stirring by a magnetic bar for 5 hours at $50^{\circ} \mathrm{C}$ to obtain homogeneous solutions. The viscosity of these polymer solutions was measured using a Brookfield DV-III ultraprogrammable rheometer (Brookfield Viscometers Ltd, Harlow, UK) with a SCV-18 spindle. These measurements were recorded with an apparent shear rate range spanning $0.053 \mathrm{~s}^{-1}-5.38 \mathrm{~s}^{-}$

${ }^{1}$. Surface tension was measured by the Wilhemly plate method and recorded with the help of a Kruss Tension Meter K9 (Kruss GmbH, Germany). Both viscosity and surface tension equipment were calibrated before use under ambient conditions $\left(\sim 25^{\circ} \mathrm{C}\right.$, humidity $\left.38.5 \%\right)$.

\subsection{Pressurised Gyration}

The experimental set up of spinning by using pressurised gyration at the ambient temperature and a humidity of $\sim 40 \%$ used in this study is shown in Figure 1. It consists of a rotary 
aluminium cylinder vessel with $\sim 60 \mathrm{~mm}$ diameter and $\sim 35 \mathrm{~mm}$ height. There are approximately 20 orifices located on the wall of vessel, and each $\sim 0.5 \mathrm{~mm}$ in diameter. The features of orifices (number, dimensions and shape) and vessel could be customized. The vessel is driven by a DC motor which connects at the bottom of vessel, and it could work in the range 4.5 to $15 \mathrm{~V}$ in order to provide various rotating speeds up to $36,000 \mathrm{rpm}$. The applied pressure (up to $3 \times 10^{5}$ $\mathrm{Pa}$ ) was provided by a nitrogen cylinder connected to the top of the vessel. A stationary aluminium foil served as the collector and was placed around the vessel which helps convenient fibre collection.

\subsection{Fibre Characterisation}

Fibre morphology and bead size (both width and length) were investigated with a JSM-6301F scanning electron microscope (SEM). Before imaging, all samples were coated with gold using a Quorum Q 150R ES sputter machine for $120 \mathrm{~s}$ in order to minimize charging effects. The micrographs were recorded at an operating voltage $5 \mathrm{kV}$ and an emission current $6 \mu \mathrm{A}$ to get high resolution pictures. Statistical analysis of average bead size (width and length) and average distance between adjacent beads in a single fibre (average inter-bead distance) was obtained from the high magnification SEM images. By using IMAGE J software, the weighted average inter-bead distance and average bead size were calculated based on $\sim 100$ measurements that were taken at different locations per coated sample, and the Gaussian distribution histograms were plotted and fitted based on the measurement results. 
The molecular structure of fibres was characterised using Fourier transform infrared spectroscopy (Perkin Elmer System 2000 FT-IR spectrometer). Analysing parameters of FTIR spectrometer were set as follows: wavenumber range $4000 \mathrm{~cm}^{-1}-400 \mathrm{~cm}^{-1}$, scanning resolution $4.0 \mathrm{~cm}^{-1}$, accumulation scans $=30$. The background spectrum was measured with nitrogen gas before testing the samples. The resulting spectrums were smoothed and plotted using Origin Pro 9.0.0.

\section{Results and Discussion}

\subsection{Characterisation of Solution Rheology}

In pressurised gyration, fibre formation is affected by the rheological properties of polymer solution and by surface tension. As the polymer concentration increased from 5 to $30 \mathrm{wt} \%$, the mean apparent shear viscosity of polymer solution increased from 64 to $15615 \mathrm{mPa}$, and the viscosity reduced as the apparent shear rate increased due to non-Newtonian shear thinning effects. The flow curves of different PCL solutions were determined in the shear rate range 0.053 to $5.38 \mathrm{~s}^{-1}$ (Figure 2), and unequivocal shear thinning was found to prevail in all solutions.

Details of the fitted power law $\left(\eta=K \gamma^{n-1}\right)$ for all polymer solutions is given in Table 1, and the flow behaviour index $(n)$ indicates that a higher polymer concentration gave stronger shear thinning.

\subsection{Fibre Morphology}

It is well known that a minimum critical polymer concentration which is related to minimum critical polymer chain entanglement is pre-requisite to successfully forming uniform fibres [17- 
20]. The increase in the solution viscosity increases the physical chain interlocking of the polymers. This interlocking of polymer chains act in a similar way to chemical cross-links and plays a crucial role in stabilising the polymer jet which together with solvent evaporation controls the process of fibre generation in pressurised gyration. But the difference is the existing relative sliding between polymer chains which affects the viscoelasticity of solutions $[9,19]$. The entanglement of polymer chain largely suppresses jet formation [20] and within a certain viscosity range, when the viscosity of polymer solution is increased up to a critical value, the fibre diameter increases as well, and the relaxation time needed for the elongation of polymer jet increases due to the incremental amounts of physical entanglement between polymer chains. Yet the polymer jet could still keep a certain shape post-stretching and finally forms bead free uniform fibre [21, 22], but if the viscosity approaches and drops below the critical value, fibres with bead on string structure will be formed.

Figure 3 (a-e) shows the bead size/average inter-bead distance distribution and SEM images of products generated by $5 \mathrm{wt} \%, 10 \mathrm{wt} \%, 15 \mathrm{wt} \%, 20 \mathrm{wt} \%$ and $25 \mathrm{wt} \%$ solutions at 36,000 rpm rotation speed and without the application of any pressure. The $30 \mathrm{wt} \%$ solution was not spinnable as gelation occurred. The related measurements from these observations include the range of bead width (BW), bead length (BL), average bead width (ABW) and average bead length (ABL), and average distance between two adjacent beads (AD). These are given in Table 2 for each polymer concentration. Due to the ribbon-like fibres and products generated 
by the $15 \mathrm{wt} \%, 20 \mathrm{wt} \%$ and $25 \mathrm{wt} \%$ solutions, respectively, the inter-bead distances for these three solutions were not measurable. When the solution's viscosity is very low, surface tension (Table 3) is the main factor that affects fibre morphologies, with higher surface tension giving more beaded or bead on string structures $[1,23]$.

Low concentration solutions i.e. $5 \mathrm{wt} \%$ and $10 \mathrm{wt} \%$ give bead on string fibres. The SEM images of products from the $10 \mathrm{wt} \%$ PCL revealed a higher density of beads distributed on the fibres and more filaments connecting the beads, and compared with the spherical beads produced by $5 \mathrm{wt} \%$ solution, the morphology of beads of the $10 \mathrm{wt} \%$ solution shows a trend of changing to an oblong structure. The fibre sizes measured for $5 \mathrm{wt} \%$ and $10 \mathrm{wt} \%$ are $3 \pm 1 \mu \mathrm{m}$ and $23 \pm 8 \mu \mathrm{m}$, respectively. Literally, in a certain range of viscosity (below the critical value of PCL concentration for the formation of bead free uniform fibres), the more viscous solutions will impose a higher resistance against the destabilising centrifugal force and dynamic fluid blowing, which will promote a larger bead size, thicker fibre, and longer distance between adjacent beads [22]. The product of $5 \mathrm{wt} \%$ PCL solution has a more irregular morphology and larger average bead size, that is $\sim 658 \mu \mathrm{m}$ in width and $\sim 756 \mu \mathrm{m}$ in length, compared with the product of $10 \mathrm{wt} \%$ PCL solution $(\sim 145 \mu \mathrm{m}$ in width and $\sim 157 \mu \mathrm{m}$ in length). Moreover, the average inter-bead distance of the product of the $5 \mathrm{wt} \%$ solution $(\sim 699 \mu \mathrm{m})$ is higher than the $10 \mathrm{wt} \%$ solution $(\sim 364 \mu \mathrm{m})$. This is because gyration caused the formation of a polymeric web in a very short time and due to the higher solvent content in $5 \mathrm{wt} \%$ solution, the freshly 
generated wet beads and filaments accumulated with the others in the vicinity to form larger/thicker beads/fibres. Evidence of agglomeration is clearly observed in Figure 3 (a) (see arrow), which cannot be found in the SEM images of $10 \mathrm{wt} \%$ solution product. The bead width for the highlighted region beneath the arrow in Figure 3 (a) was measured and found to be between $\sim 58$ to $\sim 121 \mu \mathrm{m}$ (average is $\sim 85 \mu \mathrm{m}$ ). The bead length spanned a range from $\sim 95$ to $\sim 145 \mu \mathrm{m}$ (average $\sim 121 \mu \mathrm{m}$ ). The size distributions (Figure 3a-b, Table 2) indicates the polydispersity of bead size for $5 \mathrm{wt} \%$ and $10 \mathrm{wt} \%$ solutions is $30 \%$ and $26 \%$, it also gives polydispersity of the inter-bead distance distribution to be $43 \%$ and $33 \%$, respectively. The $15 \mathrm{wt} \%$ solution generated a ribbon-like structure and beads rarely appeared (Figure 3 (c)). The amount of chain entanglement becomes greater as the solution viscosity increases, thus the relaxation time of polymer solution will be high enough to allow it to retain a certain shape during stretching to finally form a fibre like structure (bead on string or ribbon). The beads formed in low viscosity solutions shows a spherical shape, and as solution viscosity increases, it was stretched by the centrifugal force into an oblong and an increasingly ribbon-like structure. In addition, the density of beads were decreased and finally disappear altogether to form bead free fibres, and subsequently the fibres become thicker as the result of continuously increasing solution viscosity.

Beads with short fibres were formed by spinning $20 \mathrm{wt} \%$ and $25 \mathrm{wt} \%$ solutions as seen in Figures 3d and e, which gave beads of $\sim 465 \mu \mathrm{m}, \sim 648 \mu \mathrm{m}$ in width and $\sim 714 \mu \mathrm{m}, \sim 1065 \mu \mathrm{m}$ 
in length, respectively. This is attributed to the viscosity of these solutions (Table 1) which hindered solvent evaporation, so that the polymer jets have no time to be stretched into fibres before break up due to the centrifugal force overcoming the limited tensile strength of any initially-formed polymer skeleton at the liquid-air interface. The tapered tail (see arrow in Figure 3(e)) indicated the trace of this plastic deformation. The final products will still contain relatively high solvent content particularly in the interior when they reach the collector, which could explain why the products morphologies of $20 \mathrm{wt} \%$ and $25 \mathrm{wt} \%$ solutions were much more plate-like. The bead-on-string structures are widely used in drug and protein delivery where they have higher surface area to volume ratio. The short fibres and the other intermediate structures are useful as reinforcements of composite materials in structural and engineering applications. The uniform bead free fibre structures have numerous applications, for example as high efficiency filtering membranes and protective clothing due to its high large specific surface area, narrow mesh apertures and good mechanical properties [24, 25].

The influence of gyration pressure in generating fibre morphologies was studied by fixing the rotation speed at $36,000 \mathrm{rpm}$ (highest) and conducting experiments at $1 \times 10^{4}, 2 \times 10^{4}, 3 \times 10^{4} \mathrm{~Pa}$ for $10 \mathrm{wt} \%$ and $15 \mathrm{wt} \%$ solutions (Figure 4(a-d) and Table 4). By applying pressure, solvent evaporation can be enhanced as it changes the relative speed of gas flow at the liquid-air interface in the generated polymer drops. Compared with the products of the same solution without added pressure, it can be concluded that the morphologies of fibres changed 
significantly. However, the 20 and $25 \mathrm{wt} \%$ solutions did not generate any products, the polymer simply solidified at the fibre generating orifices. The $5 \mathrm{wt} \%$ solution also did not generate any structures.

Figure 4 (a) shows the product of the $10 \mathrm{wt} \%$ solution made at $1 \times 10^{4} \mathrm{~Pa}$ pressure, and here a bead on string structure was obtained with a lower bead density and the total amount of products was low, the polydispersity of the bead size distribution is $15 \%$ (Table 4). The fibre size obtained was $8 \pm 4 \mu \mathrm{m}$ and $19 \pm 8 \mu \mathrm{m}$ for 10 and $15 \mathrm{wt} \%$ solutions, respectively. The formation of much larger irregular beads ( $213 \mu \mathrm{m}$ in width, $\sim 244 \mu \mathrm{m}$ in length) was probably caused by agglomeration, compared with those formed when no pressure was applied. When the pressure applied was increased further to $2 \times 10^{4} \mathrm{~Pa}$ and $3 \times 10^{4} \mathrm{~Pa}$, no product was formed, the polymer simply solidified at the vessel orifices.

For the $15 \mathrm{wt} \%$ solution at $1 \times 10^{4} \mathrm{~Pa}$ pressure, a bead on string structure was formed rather than ribbons (Figure 4 (b)). The obtained products contained different fibre diameters and a wide range of bead sizes $(\sim 318 \mu \mathrm{m}$ average width and $\sim 351 \mu \mathrm{m}$ average length), the agglomeration between beads and inter-fibre fusion at the point of contact between fibres were significantly enhanced, and compared to $10 \mathrm{wt} \%$, the density of beads had decreased and larger size irregular beads were seen in the microstructure. This is because of applying pressure during spinning; the introduced gas stream enhances the instability of polymer jets at the jetting orifices which helps to promote bead formation. It also facilitates the volatile solvent (acetone) evaporation 
that takes place in the radial direction of jets. Hence a sharp separation of solid and liquid phase occurs and this leads to collapse at the surface [26] as shown in Figure 4(b). As shown in Figure 4 (b) and (d), the bead size and inter-bead distance value were positively skewed, and it is obvious that a narrower size distribution was obtained at a higher applied pressure. The bead size polydispersity is $34 \%, 13 \%$ and $12 \%$, and the inter-bead distance polydispersity is 46\%, 23\% and 15\% for the pressures indicated in Figure 4, respectively. A striking relationship between polymer concentration, applied pressure, average inter-bead distance, and bead size is clearly seen (Table 4).On the whole, increasing applied pressure accelerates solvent evaporation, hence the larger average size, wider size range of beads and narrower average inter-bead distances were obtained (Figures $5 \mathbf{a}$ and $\mathbf{b}$ ). In addition, compared with no pressure applied, the stretched polymer jets at the emerging orifices solidified quickly, i.e. lack of stretching time and an ascending trend of the quantity of polymer formed at the orifices as the pressure increases. With the $15 \mathrm{wt} \%$ solution increasing the pressure to $4 \times 10^{4} \mathrm{~Pa}$ was attempted, but there was no product to collect except a relatively large amount of solidified polymer. The $5 \mathrm{wt} \%$ solution was not used in pressurised experiments as it did not result in a solid structure as in the case without applied pressure.

The results here also strongly suggest that the applied pressure has significant influence on the as-spun fibre morphology, and an increased polymer concentration will decrease bead on string formation [26]. With the polymer concentration increasing, the bead size, fibre diameter and 
average inter-bead distance also increased in both the 10 and $15 \mathrm{wt} \%$ solutions at the same forming conditions. Therefore, as the solvent properties are constant, this can be attributed to the higher polymer concentration which hinders solvent evaporation, hence it leads to both a smaller relaxation time and evaporation duration during stretching. The wrinkled beads and dimpled beads shown in the SEM images (Figures 6 (a-d)) suggest that they may be caused by varying molecular weight and concentration of polymer solutions [27].

The basic forces governing pressurised gyration spinning consist of dynamic fluid flow and centrifugal. Thus, the polymer jets will be accelerated by the centrifugal force and further enhanced by gas blowing. The combination of these two against the solution's surface tension enables fibre formation. Generally, the centrifugal force will increase with higher rotation speed [20], and normal stresses in the non-Newtonian fluid exist, which in contrast to shear stresses, causes the stresses to act in the same direction as the deformation plane [21]. The change in rotation speed during gyration determines the final fibre diameter. The viscosity of solution can vary during gyration due to a temperature gradient occurring through the polymer jets during solvent evaporation, and this could also be facilitated by increasing rotation speed [14]. Mahalingam and Edirisinghe [14] have indicated that the time constant of shearing forces applied on polymer jets during pressurised gyration will be decreased with increasing rotation speed. In addition, the time constant of shearing forces governs the responses of polymer chains, i.e. higher the time constant the longer viscous response of polymer solution, and vice versa. 
Pressurised gyration was also carried out at different rotation speed in the case of 10 and 15 wt $\%$ solutions at a fixed applied pressure of $1 \times 10^{4} \mathrm{~Pa}$. Under these conditions, both these solutions formed bead on string structures, and the microstructural features are reported in Table 5. For comparison, the results obtained at $36,000 \mathrm{rpm}$ rotation speed and $1 \times 10^{4} \mathrm{~Pa}$ pressure are also listed here. When changing the rotating speed from $10000 \mathrm{rpm}$ to $24000 \mathrm{rpm}$, the fibre size measured for $10 \mathrm{wt} \%$ solution is $8 \pm 2 \mu \mathrm{m}$ and $6 \pm 2 \mu \mathrm{m}$ respectively. A transformation of bead morphology from spherical to oblong was observed for both 10 and 15 wt\% polymer solutions when increasing the rotation speed from $10,000 \mathrm{rpm}$ to $36,000 \mathrm{rpm}$ (Figures 6 (a-d)). The $10 \mathrm{wt} \%$ solution gave $\sim 275 \mu \mathrm{m}$ in bead width and $\sim 278 \mu \mathrm{m}$ in bead length at 10,000 rpm, and $\sim 250 \mu \mathrm{m}$ in bead width and $\sim 253 \mu \mathrm{m}$ in bead length at $24,000 \mathrm{rpm}$. The average inter-bead distance increased from $\sim 272$ to $\sim 289 \mu \mathrm{m}$. The same trend also can be found in the results of $15 \mathrm{wt} \%$ solution. Table 5 also shows the distribution of bead size and distance for different rotation speeds and it is evident that a narrower size distribution is obtained at a higher rotation speed. The polydispersity is $30 \%, 27 \%$ for $10 \mathrm{wt} \%$ of polymer, and $39 \%, 27 \%$ for $15 \mathrm{wt} \%$ of polymer at rotation speeds of 10,000 and $24,000 \mathrm{rpm}$, respectively; the polydispersity of inter-bead distance is $27 \%, 41 \%$ for $10 \mathrm{wt} \%$ of polymer, and $32 \%, 33 \%$ at $15 \mathrm{wt} \%$ for polymer at rotation speeds of 10,000 and 24,000 rpm, respectively. Figures 7(a and $b$ ) indicates an enhanced thinning effect by showing a less obvious trend of reduction of bead size and an obvious increase of average inter-bead distance as the result of a higher shear 
force provided by a relatively higher rotation speed. In addition, there are large size differences existing between some adjacent beads and it can be found in several SEM images in this work e.g. Figure $6(\mathrm{~b})$. It occurs because the stretching phenomenon caused by instability and elastic recoil takes placed at the neck region formed between bead and fibre. It is probably a balance between inertia, surface tension and viscoelasticity of polymer solution [28-30].

It should be noted that temperature and humidity could vary the spinnability of solution and product morphology in pressurised gyration. Raising the spinning temperature will accelerate solvent evaporation and decreases the surface tension and viscosity of polymer solution. Meanwhile fibre surface acquires a porous structure which could be only obtained at a certain level of humidity [19]. Spinning under a high humidity environment causes heat to be partially taken away as solvent evaporates, thus it will cause the surface temperature of polymer solution to become lower than the ambient temperature, hence tiny water drops will be formed on the polymer jet surface. After the wet fibre solidifies and water drops evaporate, micropores will be formed in locations where the water drops (previously) existed. This is the reason for the holes which appeared on the beads surface (e.g. in Figure 6 (a-b)).

Figure 8 illustrates how the products produced by different increments of polymer concentration are related to the average solution viscosity. In this map, the previously mentioned lower limit of spinning falls around $5 \mathrm{wt} \%$ polymer concentration, and the upper limit is at about $20 \mathrm{wt} \%$. The region of bead on string structure occurs between $10-15 \mathrm{wt} \%$ 
for spinning PCL fibres by pressurised gyration by changing the pressure and the rotational speed.

\subsection{Molecular Structure}

PCL is a thermoplastic semi-crystalline polyester which contains five non-polar methylene groups and one polar ester group per chain link, and itis characterized by a broad band at $2850 \mathrm{~cm}^{-1}$ for stretching vibration of methyl and methylene, and the band at $\sim 1750 \mathrm{~cm}^{-1}$ signifies stretching vibration of carbonyl [31]. Post gyration, the typical absorption peaks of PCL could still be seen in all of them (Figure 9) and details are given in Table 6.

\section{Conclusions}

This work demonstrated that a variety of bead on string structures could be formed by spinning PCL/acetone solutions by pressurised gyration. By changing the working parameters (pressure and rotation speed) and solution concentration, the geometry of the obtained structures could be varied substantially.

At a fixed rotation speed and without application of pressure, fibre diameter, bead size and inter-bead distance increased with increase in solution viscosity. The lower concentration of polymer solutions, e.g. $5 \mathrm{wt} \%$, gave spherical bead on string structures but considerable agglomeration of these occurred and this promoted the presence of larger and irregular beads. The $10 \mathrm{wt} \%$ solution gave a bead on string structure with high density of spindle-like beads 
linked by many filaments. The $15 \mathrm{wt} \%$ solution generated leafy fibres rarely containing beads, it indicated that in a certain range of viscosity, polymer solutions with higher viscosities led to increasing bead size and fibre diameter as well as inter-bead distance, but at a critical value ( $\sim 15 \mathrm{wt} \%$ ), beads formation gradually disappeared and bead free fibres formed. The 20 and 25 wt\% solutions offered a novel structure i.e. beads with short fibres. It illustrated that the viscosity of $20 \mathrm{wt} \%$ solution had already exceeded the upper limit of pressurised gyration, and a region of bead on string generation was obtained in this stage.

At fixed rotation speed and changing applied pressure conditions, agglomeration was enhanced for the products of $5-15 \mathrm{wt} \%$ solutions. Bead on string structure appeared in the product of 15 wt $\%$ instead of leafy fibre, which indicated that applying pressure during spinning will promote the formation of beads. It demonstrated the region of bead on string generation can be varied by changing the working parameters of the forming process. The collapse of the surface in the products occurred due to sharp separation in solid and liquid phases as a result of solvent evaporation which was aided by the gas steam.

At fixed pressure and changing rotation speed, the structure of the products showed a less obvious trend of reduction in bead size, but there existed an obvious reduction in fibre diameter and an increment in inter-bead space. This is due to increased rotation speed which enhanced the centrifugal force. 
The molecular structure of final products were confirmed by using FT-IR, pressurised gyration

spinning did not change the chemical bonding between molecular groups in PCL polymer.

\section{Acknowledgements}

We would also like to thank the assistance of Mr Kevin Reeves (Archaeology Department in

UCL) for electron microscopy.

\section{References}

[1] M. S. Birajdar, J. Lee, Sonication-triggered zero-order release by uncorking core-shell nanofibres, Chem. Eng. J. 288 (2016) 1-8.

[2] P. Ruenraroengsak, J. M. Cook, A. T. Florence, Nanosystem drug targeting: facing up to complex realities, J. Control. Release.141 (2010) 265-276.

[3] J. P. Chen, C. H. Su, Surface modification of electrospun PLLA nanofibers by plasma treatment and cationized gelatin immobilization for cartilage tissue engineering, Acta Biomaterialia 7 (2011) 234-243.

[4] S. Varanasi, Z. X. Low, W. Batchelor, Cellulose nanofibre composite membranes biodegradable and recyclable UF membranes, Chem. Eng. J. 265 (2015) 138-146.

[5] N. Bölgen, I. Vargel, P. Korkusuz, Y. Z. Menceloğlu, E. Pişkin, In vivo performance of antibiotic embedded electrospun PCL membranes for prevention of abdominal adhesions, J. Biomed. Mater. Res. B 81 (2007) 530-543.

[6] C. Chen, G. Lv, C. Pan, M. Song, C. Wu, D. Guo, X. Wang, B. Chen, Z. Gu, Poly (lactic acid) (PLA) based nanocomposites - a novel way of drug-releasing, Biomed. Mater. 2 (2007) L1-4.

[7] S. Agarwal, J. H. Wendorff, A. Greiner, Progress in the field of electrospinning for tissue engineering applications, Adv. Mater. 21 (2009), 3343-3351.

[8] J. E. Díaz, A. Barrero, M. Márquez, I. G. Loscertales, Controlled encapsulation of hydrophobic liquids in hydrophilic polymer nanofibers by co-electrospinning, Adv. Funct. Mater.16 (2006) 2110-2116.

[9] D. Petras, P. Slobodian, V. Pavlínek, P. Sáha, D. Kimmer, In the Effect of PVAc Solution Viscosity on Diameter of PVAc Nanofibers Prepared by Technology of Electrospinning, Novel Trends In Rheology IV, AIP Publishing: 2011; pp 312-319.

[10] S. Ramakrishna, K. Fujihara, W-E. Teo, T-C. Lim, Z. Ma, An introduction to electrospinning and nanofibers, World Scientific Pub Co: 2005. 
[11] G. M. Whitesides, B. Grzybowski, Self-assembly at all scales, Science 295 (2002), 24182421.

[12]Y. Lu, H. Jiang, K. Tu, L. Wang, Mild immobilization of diverse macromolecular bioactive agents onto multifunctional fibrous membranes prepared by coaxial electrospinning, Acta Biomaterialia 5 (2009) 1562-1574.

[13] Z. M. Huang, Y. Zhang, S. Ramakrishna, C. Lim, Electrospinning and mechanical characterization of gelatin nanofibers, Polymer 45 (2004) 5361-5368.

[14] S. Mahalingam, M. Edirisinghe, Forming of polymer nanofibers by a pressurised gyration process, Macromol. Rapid. Comm. 34 (2013) 1134-1139.

[15] S. Mahalingam, B. T. Raimi-Abraham, D. Q. M. Craig, M. Edirisinghe, Formation of Protein and Protein-Gold Nanoparticle Stabilized Microbubbles by Pressurized Gyration, Langmuir 31 (2014) 659-666.

[16] S. Mahalingam, B. T. Raimi-Abraham, D. Q. M. Craig, M. Edirisinghe, Solubilityspinnability map and model for the preparation of fibres of polyethylene (terephthalate) using gyration and pressure, Chem. Eng. J. 280 (2015) 344-353.

[17] A. Bassi, J. Gough, M. Zakikhani, S. Downes, The Chemical and Physical Properties of Poly ( $\varepsilon$-caprolactone) Scaffolds Functionalised with Poly (vinyl phosphonic acid-co-acrylic acid), J. Tissue. Eng. 2 (2011) 615328.

[18] C. Luo, E. Stride, M. Edirisinghe, Mapping the influence of solubility and dielectric constant on electrospinning polycaprolactone solutions, Macromolecules 45 (2012) 46694680 .

[19] J. M. Ramos, M. T. D. M. Cruz, A. C. Costa Jr, O. Versiane, C. A. T. Soto, Fourier transform infrared spectrum: Vibrational assignments using density functional theory and natural bond orbital analysis of the bis (guanidoacetate) nickel (II) complex, Science Asia 37 (2011) 247-255.

[20] C. L. Casper, J. S. Stephens, N. G. Tassi, D. B. Chase, J. F. Rabolt, Controlling surface morphology of electrospun polystyrene fibers: effect of humidity and molecular weight in the electrospinning process, Macromolecules 37 (2004) 573-578.

[21] P. Gupta, C. Elkins, T. E. Long, G. L. Wilkes, Electrospinning of linear homopolymers of poly (methyl methacrylate): exploring relationships between fiber formation, viscosity, molecular weight and concentration in a good solvent, Polymer 46 (2005) 4799-4810.

[22] M. R. Badrossamay, H. A. McIlwee, J. A. Goss, K. K. Parker, Nanofiber assembly by rotary jet-spinning, Nano Letters 10 (2010) 2257-2261.

[23] D. S. Katti, K. W. Robinson, F. K. Ko, C. T. Laurencin, Bioresorbable nanofiber- based systems for wound healing and drug delivery: Optimization of fabrication parameters, $\mathrm{J}$. Biomed. Mater. Res. B 70 (2004) 286-296. 
[24] K. Song, Y. Zhang, J. Meng, E. C. Green, N. Tajaddod, H. Li, M. L. Minus, Structural polymer-based carbon nanotube composite fibers: Understanding the processing-structureperformance relationship. Materials 6 (2013) 2543-2577.

[25] Z. M. Huang, Y. Z. Zhang, M. Kotaki, S. Ramakrishna, A review on polymer nanofibers by electrospinning and their applications in nanocomposites, Comp. Sci. Technol. 63 (2003) 2223-2253.

[26] S. Mahalingam, G. Pierin, P. Colombo, M. Edirisinghe, Facile one-pot formation of ceramic fibers from preceramic polymers by pressurised gyration, Ceram. Int. 41 (2015) 60676073 .

[27] G. Eda, S. Shivkumar, Bead structure variations during electrospinning of polystyrene, J. Mater. Sci. 41 (2006) 5704-5708.

[28] H. C. Chang, E. A. Demekhin, E. Kalaidin, Iterated stretching of viscoelastic jets, Phys. Fluids. 11 (1999) 1717-1737.

[29] H. Fong, I. Chun, D. Reneker, Beaded nanofibers formed during electrospinning, Polymer 40 (1999) 4585-4592.

[30] M. S. Oliveira, R. Yeh, G. H. McKinley, Iterated stretching, extensional rheology and formation of beads-on-a-string structures in polymer solutions, J. non-Newtonian Fluid. Mech. 137 (2006) 137-148.

[31] H. Y. N. Holman, E. Wozei, Z. Lin, L. R. Comolli, D. A. Ball, S. Borglin, M. W. Fields, T. C. Hazen, K. H. Downing, Real-time molecular monitoring of chemical environment in obligate anaerobes during oxygen adaptive response, Proc. Natl. Acad. Sci. 106 (2009) 1259912604. 
Table 1 Power law fit for data presented in Figure 2

\begin{tabular}{cccc}
$\begin{array}{c}\text { PCL } \\
\begin{array}{c}\text { oncentration } \\
(\text { wt } \%)\end{array}\end{array}$ & $\begin{array}{c}\text { Trend line } \\
\text { equation }\end{array}$ & 年 & \\
\hline $\mathbf{5}$ & $\eta=614 \gamma^{-0.82}$ & 0.8 & 0.18 \\
\hline $\mathbf{1 0}$ & $\eta=16455 \gamma^{-0.79}$ & 0.9 & 0.21 \\
\hline $\mathbf{1 5}$ & $\eta=2719 \gamma^{-0.47}$ & 0.9 & 0.54 \\
\hline $\mathbf{2 0}$ & $\eta=3020 \gamma^{-0.16}$ & 0.9 & 0.84 \\
\hline $\mathbf{2 5}$ & $\eta=8558 \gamma^{-0.11}$ & 0.9 & 0.89 \\
\hline $\mathbf{3 0}$ & $\eta=34951 \gamma^{-0.08}$ & 0.9 & 0.92 \\
\hline
\end{tabular}

Table 2 Characteristics of spun product at each PCL concentration. Rotational speed was $36000 \mathrm{rpm}$ and no pressure was applied. BW, ABW, BL, ABL and AD are defined in the text.

\begin{tabular}{|ccclcc|}
\hline $\begin{array}{c}\text { PCL } \\
\begin{array}{c}\text { concentration } \\
\text { (wt\%) }\end{array}\end{array}$ & $\begin{array}{c}\text { BW range ABW } \\
(\mu \mathrm{m})\end{array}$ & $\begin{array}{c}\text { ABW } \\
(\mu \mathrm{m})\end{array}$ & $\begin{array}{l}\text { BL range } \\
(\mu \mathrm{m})\end{array}$ & $\begin{array}{c}\text { ABL } \\
(\mu \mathrm{m})\end{array}$ & $\begin{array}{c}\text { AD } \\
(\mu \mathrm{m})\end{array}$ \\
\hline $\mathbf{5}$ & $428-1114$ & 658 & $470-1364$ & 756 & 699 \\
\hline $\mathbf{1 0}$ & $128-183$ & 145 & $141-283$ & 157 & 364 \\
\hline $\mathbf{1 5}$ & $109-220$ & 156 & $198-298$ & 199 & - \\
\hline $\mathbf{2 0}$ & $318-597$ & 465 & $420-1077$ & 714 & - \\
\hline
\end{tabular}


Table 3 Surface tension of PCL solutions used in this work. At $25 \mathrm{wt} \%$ and $30 \mathrm{wt} \% \mathrm{PCL}$ reliable measurements were not possible as the plate was stuck to the viscous solution.

\begin{tabular}{|cc|}
\hline $\begin{array}{c}\text { PCL concentration } \\
(w \mathrm{t} \%)\end{array}$ & $\begin{array}{c}\text { Surface tension } \\
(\mathrm{m} \mathbf{N} / \mathrm{m})\end{array}$ \\
\hline Acetone only & 24 \\
\hline $\mathbf{5}$ & 25 \\
\hline $\mathbf{1 0}$ & 31 \\
\hline $\mathbf{1 5}$ & 37 \\
\hline $\mathbf{2 0}$ & 50 \\
\hline $\mathbf{2 5}$ & - \\
\hline $\mathbf{3 0}$ & - \\
\hline & \\
\hline & \\
\hline
\end{tabular}

Table 4 Influence of working pressure on characteristics of products. Rotational speed was set at $36000 \mathrm{rpm}$. BW, ABW, BL, ABL and AD are defined in the text.

\begin{tabular}{|ccccccc|}
$\begin{array}{c}\text { Polymer } \\
\text { concentration } \\
(w \mathrm{w} \%)\end{array}$ & $\begin{array}{c}\text { Pressure } \\
\left(1 \times 10^{5} \mathrm{~Pa}\right)\end{array}$ & $\begin{array}{c}\text { BW range } \\
(\mu \mathrm{m})\end{array}$ & $\begin{array}{c}\text { ABW } \\
(\mu \mathrm{m})\end{array}$ & $\begin{array}{c}\text { BL range } \\
(\mu \mathrm{m})\end{array}$ & $\begin{array}{c}\text { ABL } \\
(\mu \mathrm{m})\end{array}$ & AD $(\mu \mathrm{m})$ \\
\hline $\mathbf{1 0}$ & 0.1 & $107-324$ & 213 & $101-347$ & 244 & 310 \\
\hline $\mathbf{1 0}$ & 0.2 & - & - & - & - & - \\
\hline $\mathbf{1 5}$ & 0.1 & $140-438$ & 318 & $195-485$ & 351 & 473 \\
\hline $\mathbf{1 5}$ & 0.2 & $206-1102$ & 544 & $250-1589$ & 626 & 347 \\
\hline $\mathbf{1 5}$ & 0.3 & $281-1491$ & 581 & $614-1900$ & 1103 & 314 \\
\hline
\end{tabular}


Table 5 Influence of rotational speed on characteristics of products. The working pressure was set at $1 \times 10^{4} \mathrm{~Pa}$. BW, ABW, BL, ABL and AD are defined in the text.

\begin{tabular}{|ccccccc|}
$\begin{array}{c}\text { Polymer } \\
\text { concentration } \\
(w t \%)\end{array}$ & $\begin{array}{c}\text { Rotation } \\
\text { Speed } \\
(\mathrm{rpm})\end{array}$ & $\begin{array}{c}\text { BW range } \\
(\mu \mathrm{m})\end{array}$ & $\begin{array}{c}\text { ABW } \\
(\mu \mathrm{m})\end{array}$ & $\begin{array}{c}\text { BL range } \\
(\mu \mathrm{m})\end{array}$ & $\begin{array}{c}\text { ABL } \\
(\mu \mathrm{m})\end{array}$ & $\begin{array}{c}\text { AD } \\
(\mu \mathrm{m})\end{array}$ \\
\hline $\mathbf{1 0}$ & 10000 & $158-355$ & 275 & $204-460$ & 278 & 272 \\
\hline $\mathbf{1 0}$ & 24000 & $134-350$ & 250 & $141-393$ & 253 & 289 \\
\hline $\mathbf{1 0}$ & 36000 & $107-324$ & 213 & $101-347$ & 244 & 310 \\
\hline $\mathbf{1 5}$ & 10000 & $173-532$ & 347 & $250-595$ & 379 & 330 \\
\hline $\mathbf{1 5}$ & 24000 & $168-489$ & 343 & $196-531$ & 371 & 399 \\
\hline $\mathbf{1 5}$ & 36000 & $140-438$ & 318 & $195-485$ & 351 & 473 \\
\hline
\end{tabular}

Table 6 Typical PCL infrared spectrum bands

\begin{tabular}{|cc|}
\hline Position $\left(\mathrm{cm}^{-1}\right)$ & Vibrator \\
\hline 2941 & Asymmetric stretching vibration of $\mathrm{CH}_{2}$ \\
\hline $\mathbf{2 8 6 2}$ & Symmetric stretching vibration of $\mathrm{CH}_{3}$ \\
\hline $\mathbf{1 7 2 0}$ & Stretching vibration of $\mathrm{C}=\mathrm{O}$ \\
\hline $\mathbf{1 4 7 3}$ & Flexural/bending vibration of $\mathrm{CH}_{2}$ \\
\hline $\mathbf{1 3 8 0}$ & Flexural/bending vibration of $\mathrm{CH}_{3}$ \\
\hline $\mathbf{1 1 6 9} \& \mathbf{1 0 6 1}$ & Symmetric stretching vibration of $\mathrm{COC}$ \\
\hline $\mathbf{9 5 3}$ & Wagging/rocking vibration of $\mathrm{CH}_{2}$ \\
\hline
\end{tabular}




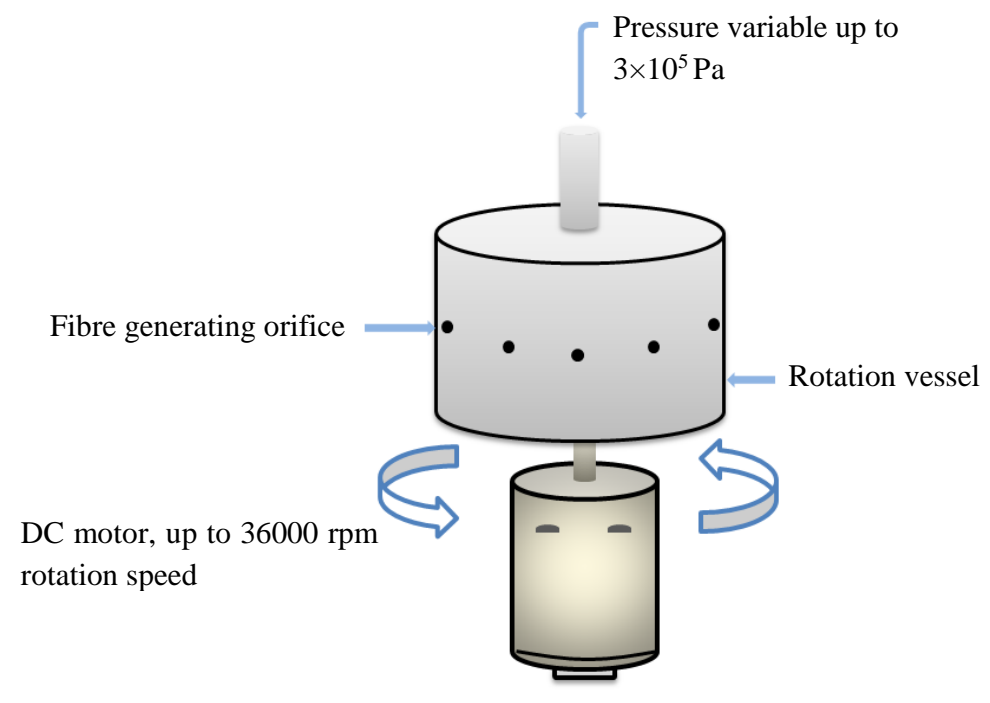

Figure 1 Process of pressurised gyration spinning 


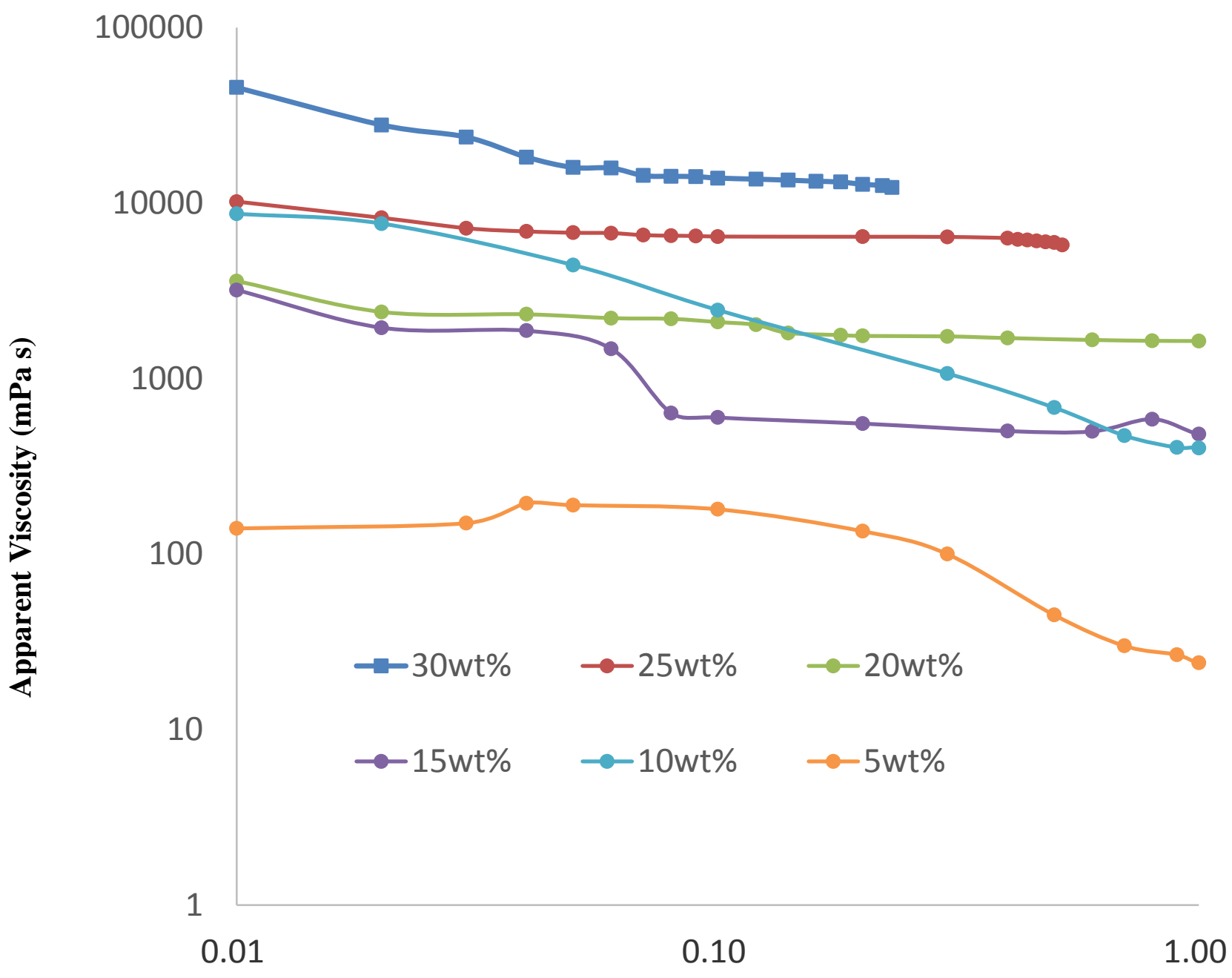

Shear Rate $\left(\mathbf{s}^{-1}\right)$ 


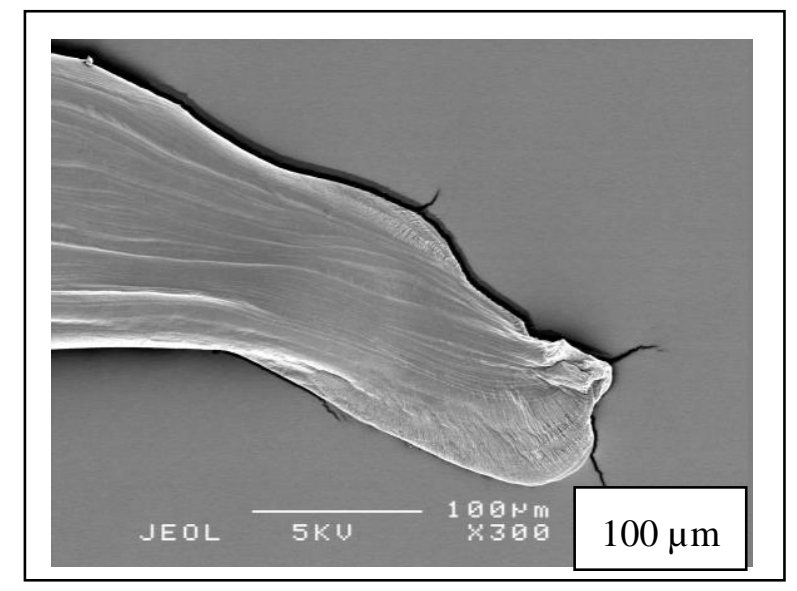

(e)

Figure 3 Scanning electron micrographs of products made using the PCL solutions at 36000rpm rotation speed and without pressure: (a-b) bead on string structure formed with 5 and $10 \mathrm{wt} \%$ solutions; (c) ribbon-like fibre formed by the $15 \mathrm{wt} \%$ solution; (d-e) elongated beads with short fibres formed by 20 and 25 wt\% solutions. Inset in (a-b) show bead size distribution with $\mathrm{Y}$ and $\mathrm{X}$ axis, frequency and bead size range, respectively.
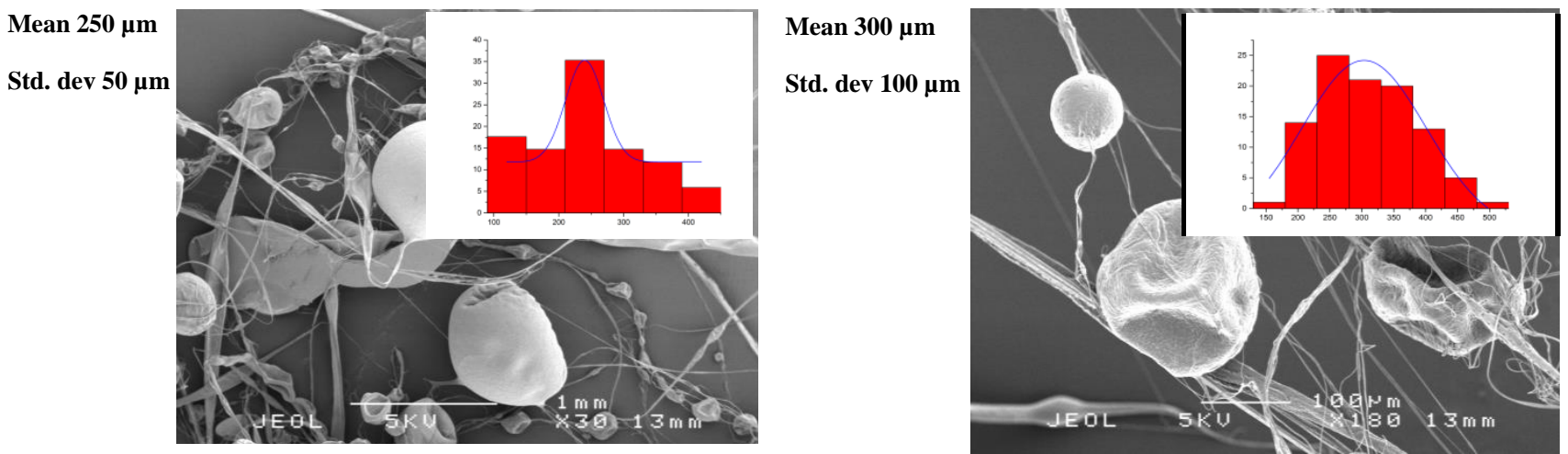

(a) 

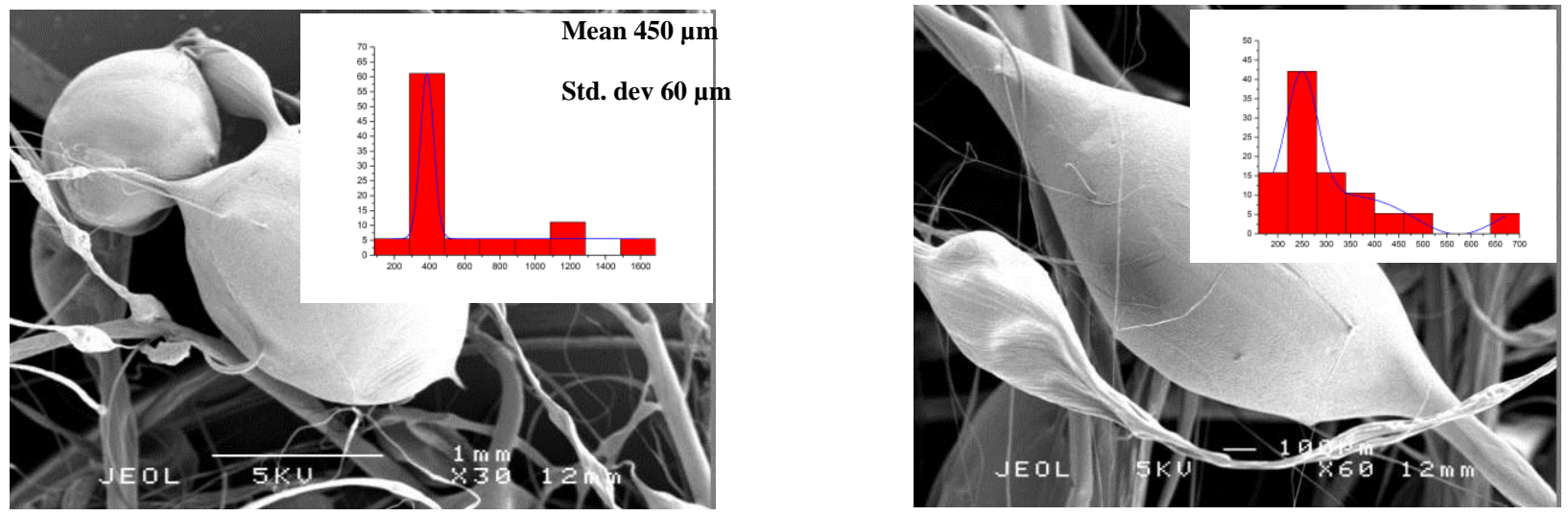

(d)

Figure 4 Scanning electron micrographs of products showing bead width and inter-bead distance for $10 \mathrm{wt} \%$ and $15 \mathrm{wt} \%$ solution products at a pressure $1 \times 10^{4}$ to $3 \times 10^{4} \mathrm{~Pa}$, and fixed rotation speed at 36,000 $\mathrm{rpm}$ : (a) $10 \mathrm{wt} \%$ solution with $1 \times 10^{4} \mathrm{~Pa}$ pressure; (b) $15 \mathrm{wt} \%$ solution with $1 \times 10^{4} \mathrm{~Pa}$ pressure; (c) $15 \mathrm{wt} \%$ solution with $2 \times 10^{4} \mathrm{~Pa}$ pressure; (d) $15 \mathrm{wt} \%$ solution with $3 \times 10^{4} \mathrm{~Pa}$ pressure. Inset in (a-b) show bead size distribution with $\mathrm{Y}$ and $\mathrm{X}$ axis, frequency and bead size range, respectively. 


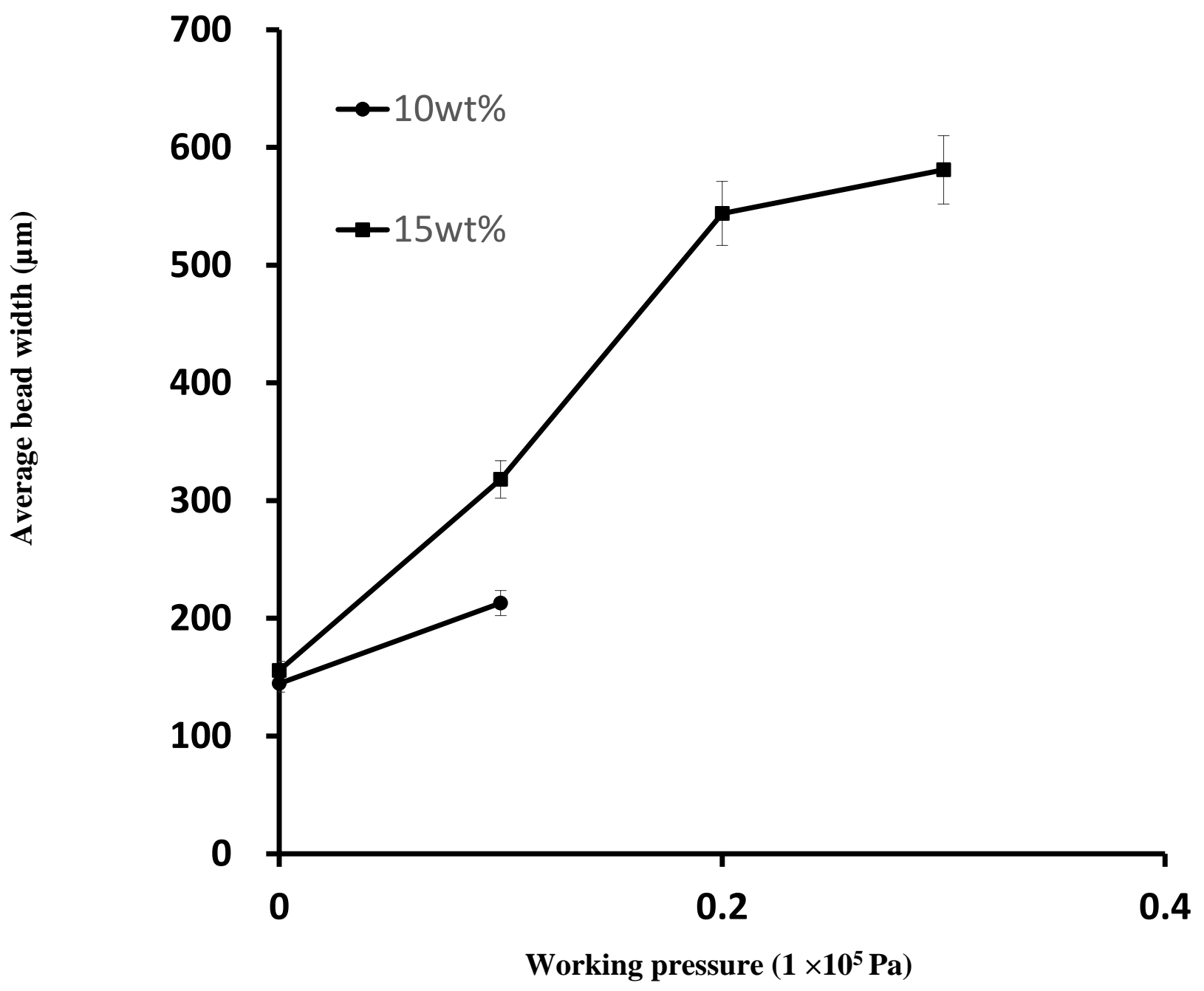

(a) 


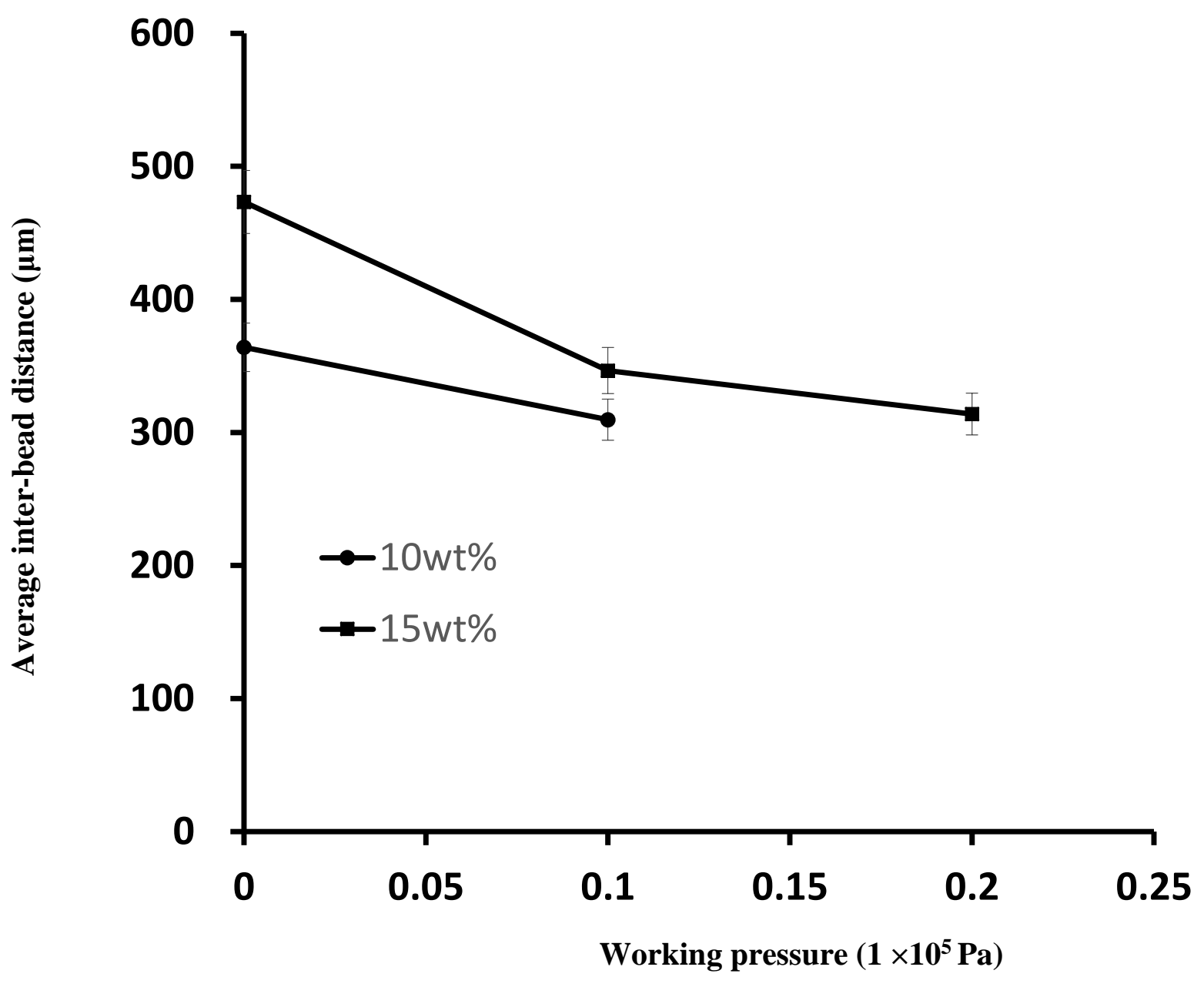

(b)

Figure 5 Relationship between (a) average bead width and working pressure for the products of different solutions; (b) average inter-bead distance and working pressure, for the products of different solutions. Rotating speed for both (a) and (b) are $36000 \mathrm{rpm}$. 

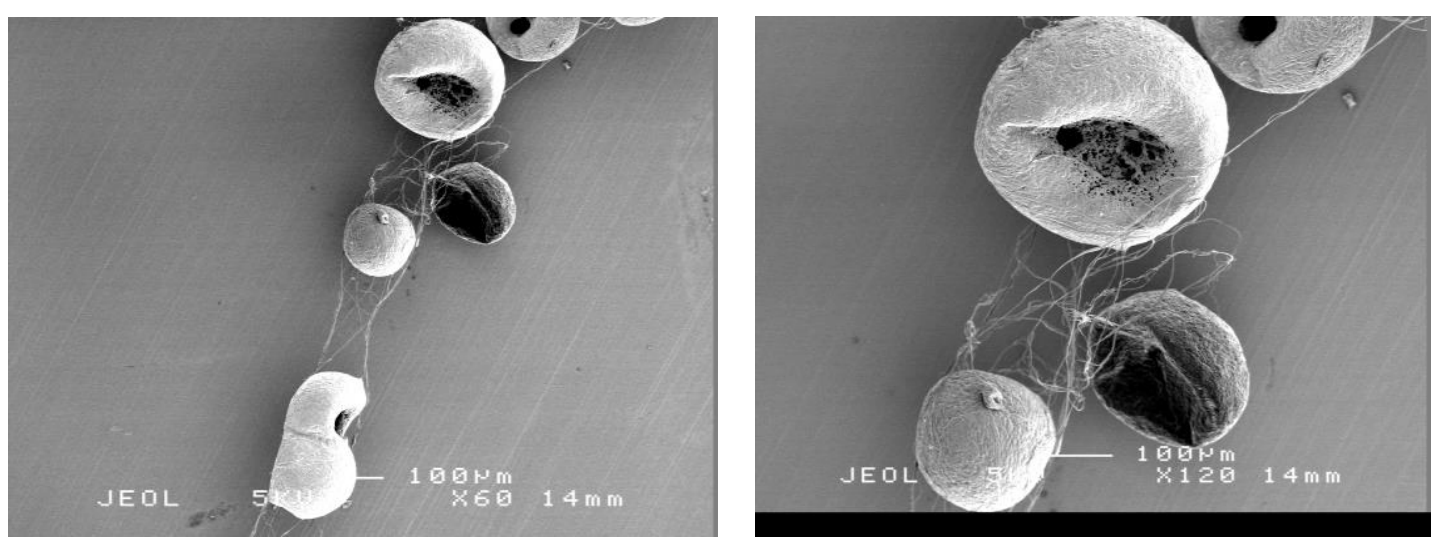

(a)
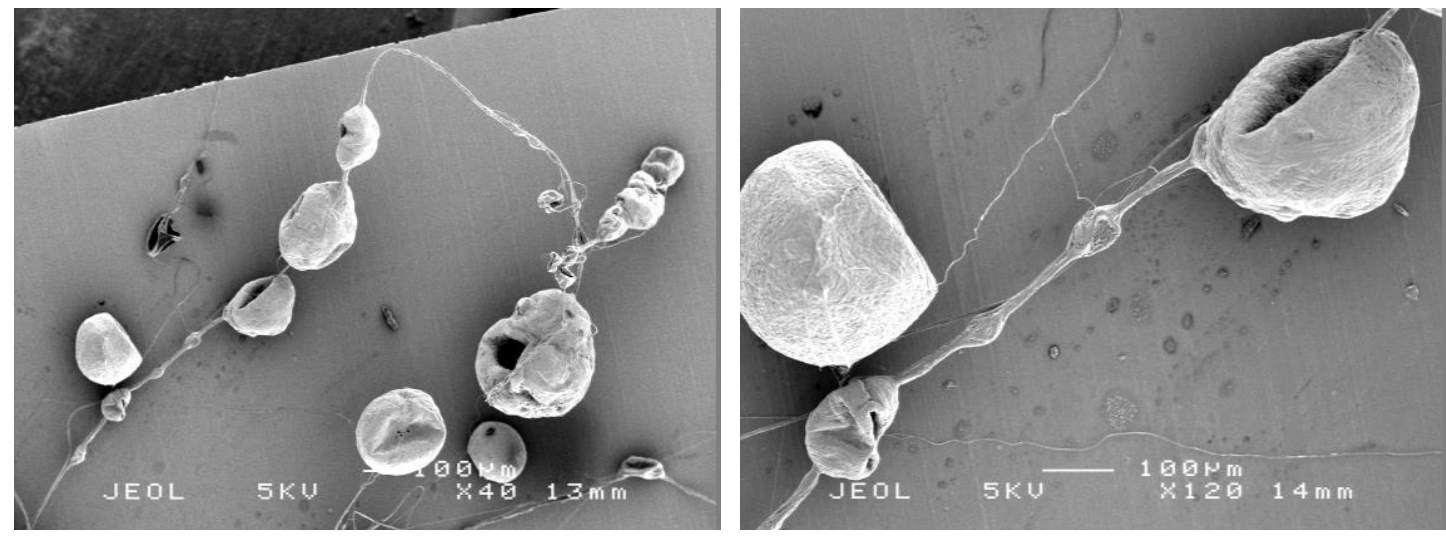

(b) 

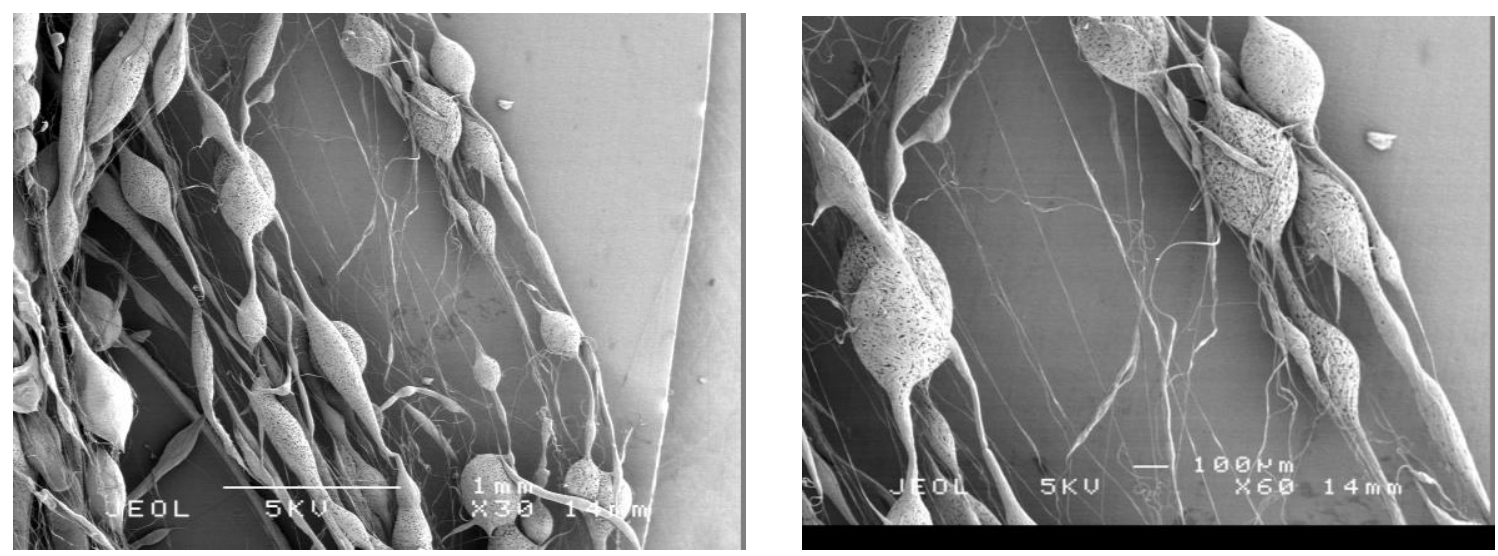

(c)
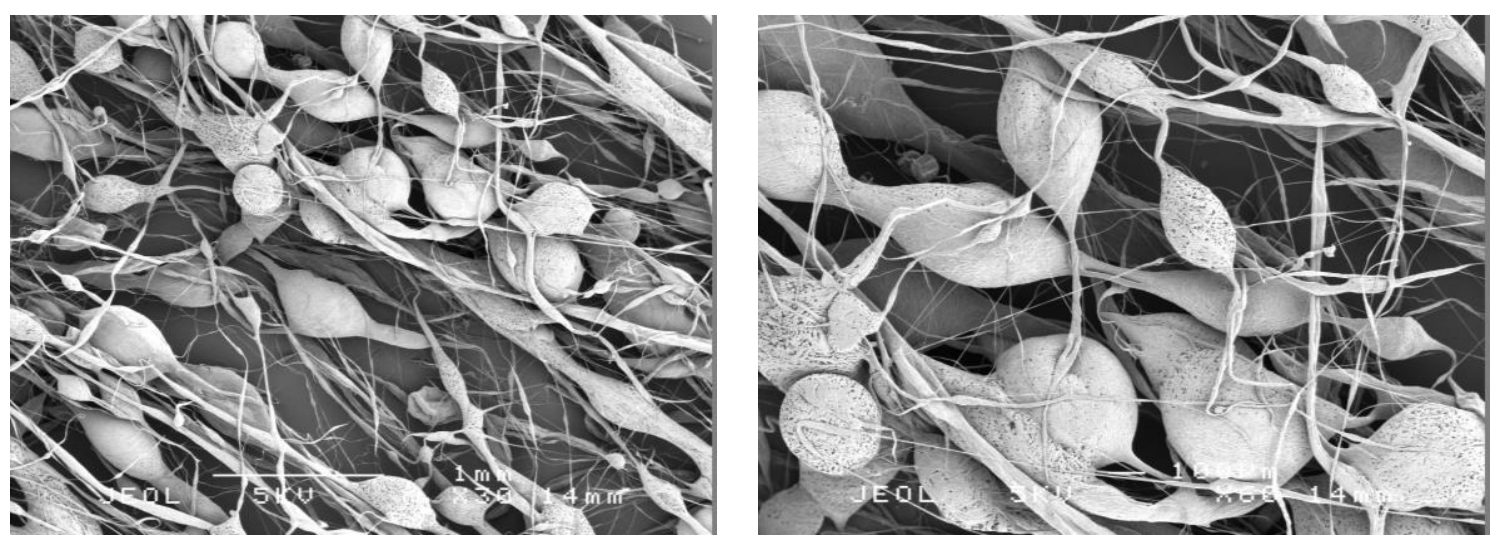

(d)

Figure 6 SEM images showing the bead width and inter-bead distance of $10 \mathrm{wt} \%$ and $15 \mathrm{wt} \%$ solution products at rotation speed ranges from $10,000 \mathrm{rpm}$ to $24,000 \mathrm{rpm}$ and a fixed $1 \times 10^{4}$ Pa working pressure: (a) $10 \mathrm{wt} \%$ solution with 10,000 rpm rotation speed; (b) $10 \mathrm{wt} \%$ solution with 24,000 rpm rotation speed; (c) $15 \mathrm{wt} \%$ solution with 10,000 rpm rotation speed; (d) 15 wt $\%$ solution with 24,000 rpm rotation speed 


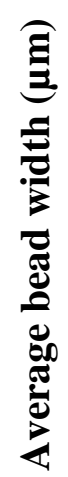

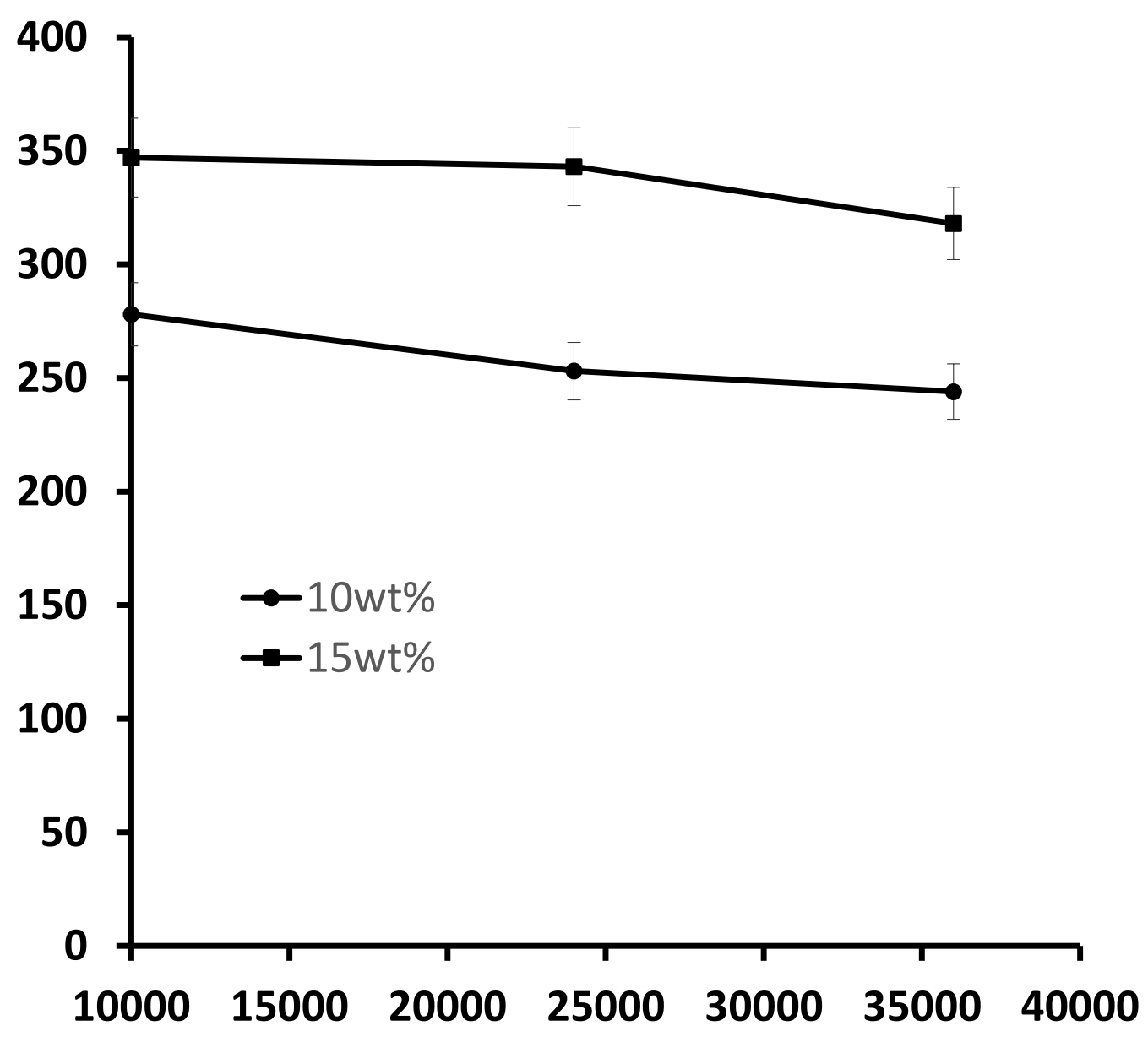

Rotational speed (rpm) 


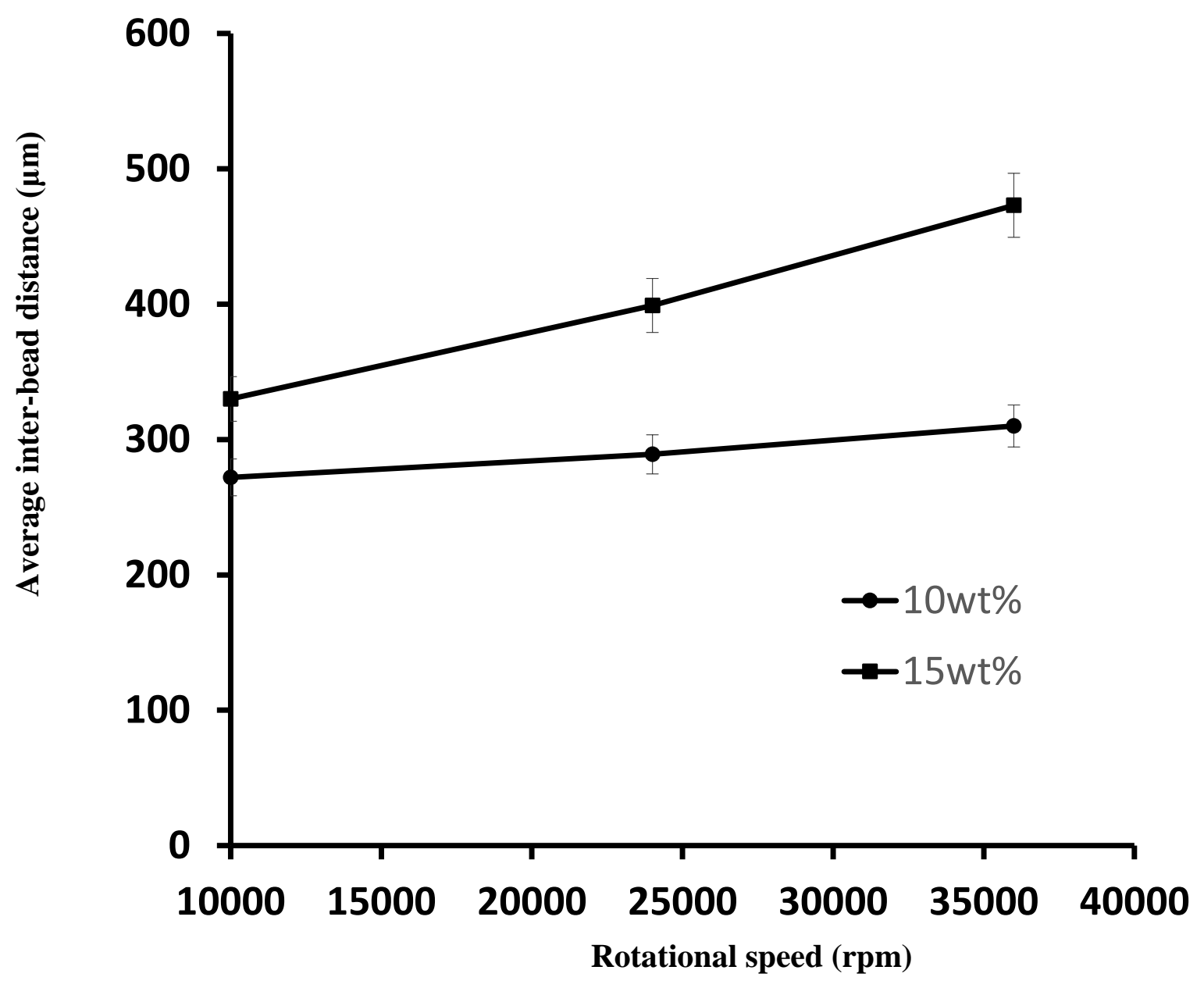

(b)

Figure 7 Relationship between (a) average bead width and rotation speed for products of different solutions; (b) average inter-bead distance and rotation speed for products of different solutions. Working pressure for both (a) and (b) are $1 \times 10^{4} \mathrm{~Pa}$. 


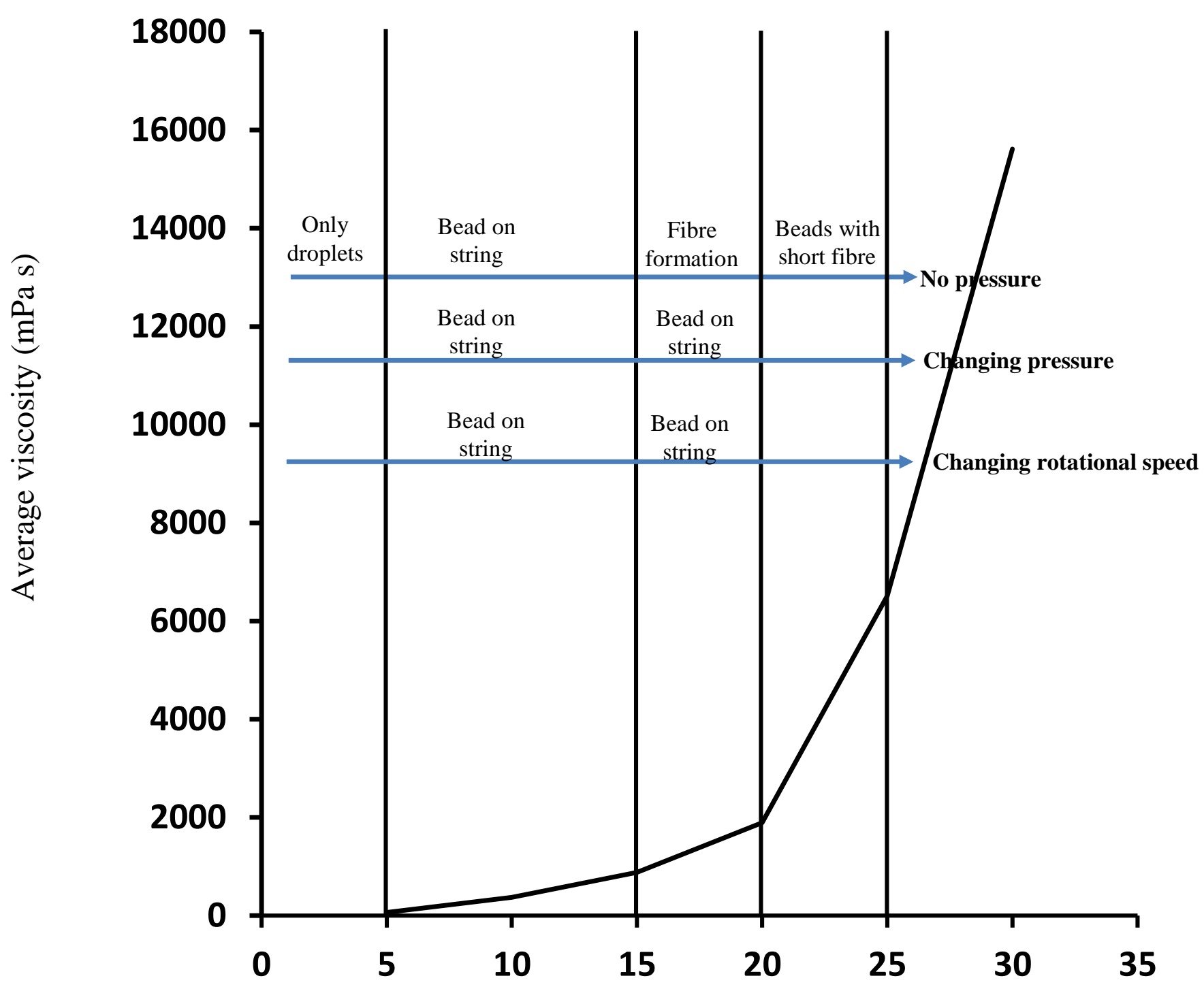

Polymer concentration (wt $\%)$

Figure 8 Viscosity - polymer concentration - product map for various conditions of gyratory forming of PCL solutions 


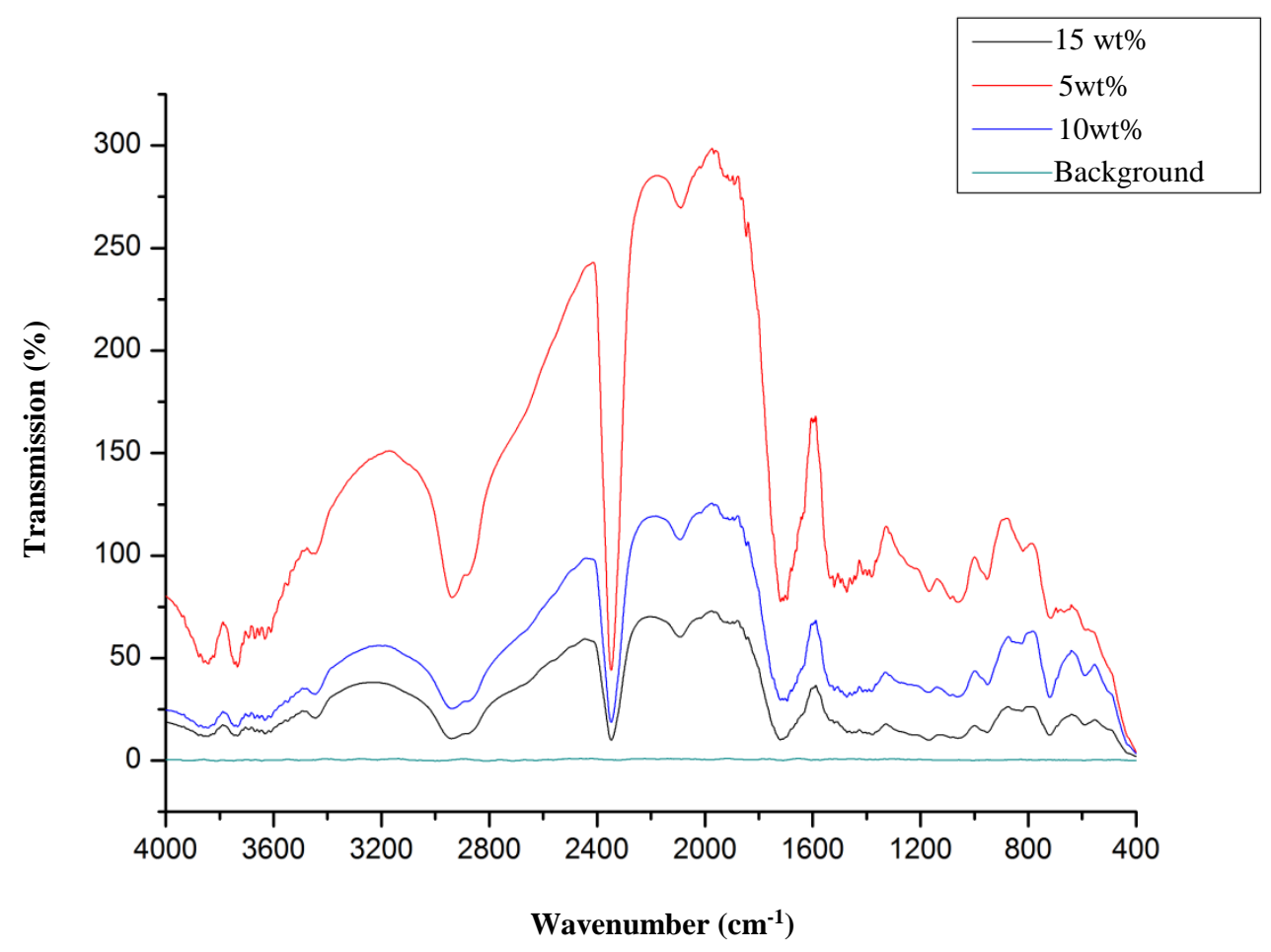

Figure 9 FT-IR spectra of PCL polymer products of $5 \mathrm{wt} \%, 10 \mathrm{wt} \%$ and $15 \mathrm{wt} \%$ solutions 


\section{Author Biographies}

Xianze Hong gained a Master of Engineering degree from University College London (UCL), UK. Currently he is a $\mathrm{PhD}$ student in the Department of Mechanical Engineering at UCL. He is attached to the Biomaterials Processing and Forming Laboratory where his research focuses on manufacturing smart polymeric materials for biomedical applications.

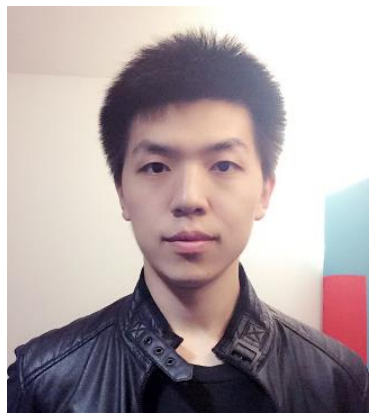

Dr Suntharavathanan Mahalingam gained his doctorate from UCL. Subsequently, he was a research associate in the Interface Analysis Centre at Bristol University, UK. Currently, he is an Engineering \& Physical Sciences Research Council (UK) supported research associate in the Department of Mechanical Engineering at UCL, where he is inventing techniques to manufacture functional polymeric fibres and smart bubbles across the scale range from micro-nano mainly for pharmaceutical and biomedical applications. He won the 2014 Materials Science \& Engineering C Young Researcher Award.

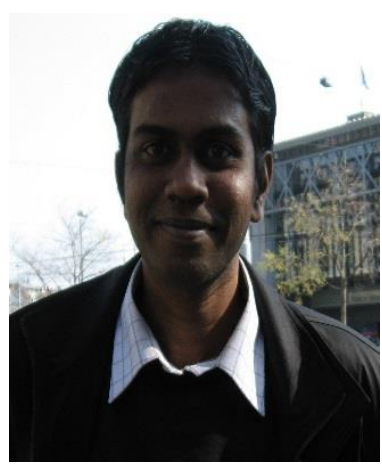


Mohan Edirisinghe DSc holds the Bonfield Chair of Biomaterials in the Department of Mechanical Engineering at University College London. He has published over 350 journal papers and his most recent research is on creating novel techniques for the preparation of particles, bubbles, capsules and fibres. Together with Dr Mahalingam, they invented pressurised gyration and other related sister-processes to manufacture novel polymeric structures. He has been awarded many prizes for his research including the Royal Society Brian Mercer Feasibility Award for an unprecedented three times (2005, 2009 and 2013).

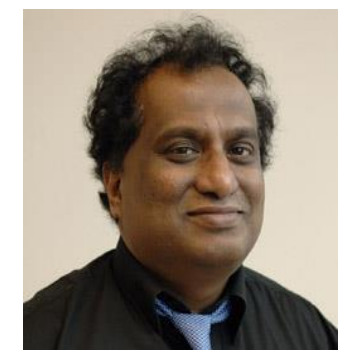

